\title{
UTILIZAÇÃO DE UM MODELO DE PROGRAMAÇÃO INTEIRA NO DIMENSIONAMENTO DE FROTA DE UM OPERADOR LOGÍSTICO: UM ESTUDO DE CASO
}

\section{USE OF AN ENTIRE PROGRAMMING MODEL IN THE FLEET DIMENSIONING OF A LOGISTIC OPERATOR: A CASE STUDY}

\author{
André Andrade Longaray* E-mail: longaray@yahoo.com.br \\ Rafael Rolim Guerreiro* E-mail: rolimguerreiro@yahoo.com.br \\ Ticiani Gonçalves Chaves*E-mail: ticiani.chagon@gmail.com \\ Paulo Roberto Munhoz" paulorsmunhoz@gmail.com \\ Vilmar Antônio Gonçalves Tondolo* E-mail: vtondolo@gmail.com - \\ *Universidade Federal do Rio Grande (FURG), Rio Grande, RS \\ Universidade Federal de Pelotas (UFPEL), Pelotas, RS
}

\begin{abstract}
Resumo: O presente artigo relata o estudo sobre o dimensionamento e planejamento da logística envolvendo decisões em níveis estratégicos e táticos de uma frota heterogênea de caminhões de carga, pertencentes a um operador logístico, que tem sua unidade localizada na Bahia e atende a região nordeste do Brasil. O trabalho tem por objetivo apresentar a utilização de um modelo de programação inteira, que dimensiona o tamanho ideal da frota e define em quais rotas esses veículos devem ser utilizadas, assim como a viabilidade econômica da posse de uma frota própria. Quanto ao delineamento da pesquisa, a mesma se enquadra como um estudo de caso, sendo esse método uma estratégia de pesquisa que busca examinar um fenômeno contemporâneo dentro de seu contexto, sendo utilizada de maneira descritiva. Para chegar à solução do problema, encontrando o dimensionamento ideal da frota, usou-se um modelo algoritmo de programação inteira com o propósito de identificar as características e particularidades da empresa, a fim de minimizar os custos totais de transporte e indicando quais clientes cada caminhão deve atender. O modelo foi testado no espaço de doze meses e os resultados obtidos indicam uma redução média de $59 \%$ nos custos totais de transporte quando comparados com os dados reais da empresa estudada.
\end{abstract}

Palavras-chave: Logística. Dimensionamento de frota. Programação inteira. Terceirização. Transporte.

Abstract: This paper reports on the study of the design and planning of logistics involving strategic and tactical levels of a heterogeneous fleet of cargo trucks, belonging to a logistic operator, whose unit is located in Bahia and serves the northeast region of Brazil. The objective of this work is to present an integer programming model, which measures the ideal size of the fleet and defines the routes in which these vehicles are to be used, as well as the economic feasibility of owning a fleet of its own. As for the research design, it is considered as a case study, being this method a research strategy that seeks to examine a contemporary phenomenon within its context, being used in a descriptive way. In order to arrive at the solution of the problem, by finding the optimal fleet dimensioning, an integer programming model was used to identify the characteristics and peculiarities of the company in order to minimize the total transportation costs and indicate which customers each truck must attend. The model was tested within twelve months and the results indicate an average reduction of $59 \%$ in total transport costs when compared to the actual data of the company studied.

Keywords: Logistics. Fleet dimensioning. Whole programming. Outsourcing. Transport. 


\section{INTRODUÇÃO}

A logística é uma área estratégica para as empresas, administrando recursos financeiros e materiais, planejando transporte, armazenamento e distribuição. No Brasil, os gastos dispensados com essa área, segundo pesquisa realizada pela Fundação Dom Cabral e publicada em Setembro de 2014, consomem 11,2\% do PIB nacional. Grande parte deste custo se dá devido a logística de transporte rodoviário, que escoa mais de 55\% das cargas movimentadas em território nacional através de mais de um milhão e setecentos mil quilômetros de estradas e rodovias.

A palavra logística derivada do grego (logos = razão) significa "a arte de calcular" ou "a manipulação dos detalhes de uma operação", ou do francês (loger = abrigar). As origens da logística são de natureza estritamente militar, onde nesse contexto representava a aquisição, armazenamento, manutenção e o transporte de pessoas e materiais, isto é, oferecia apoio à movimentação dos exércitos (PRICE \& HARRISON 2013 apud FERREIRA FILHO et al., 2015).

A evolução da logística ocorre a partir do estudo de metodologias empregadas no meio militar para assegurar a correta e adequada capacidade de mobilização, deslocamento, posicionamento e manutenção de tropas, equipamentos e suprimentos, para garantir que os exércitos tivessem capacidade de avançar e manter posições em território inimigo, permanecendo assim até o fim da Segunda Grande Guerra, tendo em seguida, passado a ser utilizada por empresas do setor de manufatura com o propósito de determinar todas as atividades destinadas a assegurar a compra correta, movimentação e a gestão de materiais (GHIANI; LAPORTE \& MUSMANNO 2013 apud FERREIRA FILHO et al., 2015).

Logística é o processo de gerenciamento estratégico de compra, do transporte e da armazenagem de matérias-primas, componentes e produtos acabados (além dos fluxos relacionados) por parte da organização e de seus canais de marketing, de tal modo que as lucratividades atual e futura sejam maximizadas mediante a entrega de encomendas com o menor custo associado (CHRISTOPHER, 2012 apud FERREIRA FILHO et al., 2015).

Dados apresentados pelo centro de estudos logísticos da UFRJ indicam um crescimento de $41 \%$ para $60 \%$ na terceirização do setor logístico na indústria de 
1998 a 2003; reflexo da abertura comercial sofrida pelo Brasil na última década do século $\mathrm{XX}$, que colocou os produtos nacionais em plena competição com os importados, focando os esforços da indústria brasileira na qualidade de seus bens oferecidos e levando à terceirização dos setores de apoio a seus objetivos-fins, dentre eles o setor logístico. Tal situação fomentou a competitividade entre os operadores logísticos, que buscam diferenciais competitivos para fidelizar seus clientes elevando seu nível de serviço sem o aumento de custos.

O desenvolvimento tecnológico da produção e a necessidade de se alcançar um número maior de consumidores onde quer que eles se encontrem no globo terrestre, com o menor custo e tempo de entrega, tornou necessário o investimento das empresas em frota de veículos e ferramentas logísticas, sendo estes próprios ou de terceiros (FERREIRA FILHO et al., 2015).

O termo terceirização foi criado na empresa gaúcha Riocell, sendo introduzido e disseminado no meio empresarial brasileiro por revistas de negócios como equivalente ao termo internacional outsourcing (EXAME 2002 apud BANDEIRA, 2009). Outsourcing é uma abreviatura para outside resource using (do inglês, uso de recursos externos) e significa criar valor fora da empresa, por meio de atividades com uso de recursos externos à organização (ARNOLD 2000 apud BANDEIRA, 2009). O terno terceirização tem sido usado para descrever a retirada de processos internos não essenciais à empresa, tais como: fornecimento de alimentos, segurança, administração patrimonial, serviços jurídicos, recrutamento, logística e sistemas de informação (HARLAND 1996 apud BANDEIRA, 2009).

$O$ aumento da terceirização logística se deve a concentração das empresas em suas atividades centrais (PHAHALAD; HAMEL 1990 apud BANDEIRA, 2009). A busca por operadores logísticos é estimulada pelo intuito de oferecer um melhor nível de serviço ao cliente e pela redução de custo (SINK; LANGLEY 1997 apud BANDEIRA, 2009).

Diante deste panorama, um estudo sobre planejamento da logística envolvendo decisões em níveis estratégicos e táticos, envolvendo composição da frota, dimensionamento da frota e modelo da gestão e distribuição (própria ou terceira), pode indicar o diferencial competitivo procurado pelos operadores logísticos anteriormente citados (FABRÍCIO \& SUBRAMANIAN, 2008). 
Valente et al. (2008) definem o termo "gestão de frota" como sendo a atividade de reger, administrar ou gerenciar um conjunto de veículos pertencentes a uma mesma empresa. Essa tarefa tem uma abrangência bastante ampla e envolve diferentes serviços, como dimensionamento, especificação de equipamentos, roteirização, custos, manutenção e renovação de veículos, entre outros. É um componente importante no processo de administração dos transportes, já que a movimentação de carga tem peso significativo na formação dos custos logísticos e na qualidade do serviço, uma vez que é a atividade final da cadeia de suprimentos (BERTAGLIA, 2008).

Ao inserir-se nesse contexto, esse trabalho tem por objetivo apresentar a utilização de um modelo de programação inteira, que dimensiona o tamanho ideal da frota e define em quais rotas esses veículos devem ser utilizadas, assim como a viabilidade econômica da posse de uma frota própria em um operador logístico localizado no estado da Bahia.

O presente trabalho está dividido em cinco seções. Após a presente introdução, a seção 2 que segue, apresenta a fundamentação teórica onde a pesquisa se fundamenta. Na seção 3, expõem-se os procedimentos metodológicos do trabalho. A seção 4 trata do problema, da formulação matemática, da execução do algoritmo e da análise dos resultados. Finalizando, a seção 5 apresenta as considerações finais a respeito do trabalho.

\section{REFERENCIAL TEÓRICO}

\subsection{Custos de transporte}

$\mathrm{Na}$ era da competição por mercados cada vez mais exigentes, em que as organizações bem sucedidas são aquelas que conseguem cumprir o menor prazo de coleta/entregas com o menor custo, a gestão de frota torna-se um desafio gerencial que envolve diferentes tarefas, tais como a aquisição de veículos, manutenção, gestão de clientes, contabilidade, gestão do caixa etc, tendo como foco a alocação de meios de transporte para satisfazer às demandas dos usuários conforme suas necessidades (DOPPER \& IWANOWSKI 2012 apud FERREIRA FILHO et al., 2015). 
Segundo Novaes (2001) apud Fabrício \& Subramanian (2008), os custos podem ser classificados entre fixos e variáveis. Os custos variáveis são aqueles que se alteram com a quantidade de serviços ou produtos ofertados; enquanto os custos fixos são aqueles que independem da produção.

Como exemplo de custos fixos, podemos citar: depreciação contábil, Salários e encargos da tripulação, licenciamento do veículo. No tocante aos custos variáveis, podemos citar: Combustíveis, lubrificantes, pneus, recapagens de pneus, peças e mão-de-obra para manutenção dos veículos.

Chopra \& Meindl (2009), corroboram com a visão de Novaes (2001) apontando cinco tipos de custos que influenciam as decisões sobre o transporte: Custo relacionado ao veículo, custo operacional fixo, custo relacionado à viagem, custo relacionado à quantidade, custos indiretos.

O custo relacionado ao veículo é o custo contraído pelo transportador pela compra ou aluguel do veículo usado para transportar as mercadorias, este é considerado fixo para decisões de curto prazo tomadas pelo transportador e de custo variável para decisões estratégicas tomadas para médio e longo prazo.

O custo Operacional fixo inclui todo custo contraído a portões de embarque, terminais e mão de obra, sendo os veículos utilizados ou não, Para decisões operacionais esses custos são fixos, para decisões de planejamento e estratégia que abrangem localização e tamanho das instalações esses custos são variáveis.

Custo relacionado à viagem é contraído toda vez que um veículo inicia uma viagem e inclui o preço de mão de obra e combustível, dependendo da distância da viagem e duração. Esse custo é considerado variável tanto referente as decisões estratégicas quanto operacionais tomadas pela transportadora.

Custo relacionado à quantidade se apresentam quanto ao carregamento /descarregamento e a parte do combustível gasta devido ao item que está sendo carregado, o custo é definido como variável, a menos que a mão de obra utilizada para carregar /descarregar seja fixa.

Custo indireto são os custos de planejamento e elaboração de cronograma de uma rede de transporte, bem como investimento em tecnologia da informação. Ocorre quando uma empresa de transporte investe em software de criação de rotas. 
O transporte de cargas é considerado um elemento fundamental para logística, pois assegura a ininterrupta operação de cargas ao longo da cadeia de suprimento, e pode ser definido como sendo o planejamento e a execução da movimentação de mercadorias por uma transportadora entre dois pontos com um custo efetivo e cumprimento de prazos e condições especificados pelo expedidor (GRANT, 2013 apud FERREIRA FILHO et al., 2015).

\subsection{Modelos de dimensionamento}

List (2003) apud Russiano (2010) afirma que o dimensionamento de frotas de veículos é um exemplo específico de dimensionamento de recursos reutilizáveis. $O$ mesmo complementa dizendo que os modelos de dimensionamento de uma frota costumam lidar com o seguinte problema: Dada a demanda por viagens de um veículo e as características de cada viagem (duração, insegurança. Etc.), um número ideal de veículos deverá ser necessário para satisfazer a demanda em relação a algum critério, por exemplo, a minimização do custo total.

Levando em consideração os aspectos referentes ao dimensionamento de frota de veículos, de acordo com Maia (2011) apud Silva (2012), Dimensionamento de frota baseia-se numa metodologia com uma sequência pré-definida, onde 0 levantamento de dados deve ser preciso para que não haja erro no resultado final.

Barth \& Michel (2012), ao estudar casos no dimensionamento de frota de veículos com foco na redução de custos, apontam que a literatura aborda o problema do dimensionamento de frota de três maneiras distintas: problema de roteirização, problema de complexidade matemática sem envolvimento de roteamento, baseados no tempo e ciclo dos veículos.

Roteirização de veículos é o processo utilizado para determinar um ou mais roteiros ou sequências de paradas que devem ser cumpridas visando diversos pontos de geograficamente dispersos, em locais já definidos de forma a atender a demanda (CUNHA, 2007 apud SILVA, 2012).

Manguino \& Ronconi (2012), discorrem sobre o problema de roteamento de veículos (VRP), apresentando uma formulação de programação linear para o problema de roteamento de veículos com frota mista, janelas de tempo e custos de 
escalonamento. Os autores apontam que o dimensionamento de frota foi à característica agregada ao problema clássico de VRP (Vehicle Routing Problem), que o aproximou de um caso real. Assim, cada tipo de veículo utilizado no roteamento passou a possuir sua própria capacidade de transporte, custo de aquisição e manutenção, além de custos variáveis, tanto por unidade de carga transportada quanto por distância percorrida.

Sobre o dimensionamento de frota sem abordagem de roteirização, Alvim (2004) apud Manguino \& Ronconi (2012) dão o exemplo do BPP (Bin Packing Problem), que consiste em arrumar objetos de diferentes tamanhos em um número infinito de bins (caminhões, trens, aviões etc.) com restrição de capacidade e volumes, tendo como objetivo minimizar o número de bins que contenham todos os objetos.

Valente et al. (2012) demonstram o dimensionamento de frota com base nos tempos de ciclo do veículo, utilizando cálculos que definem a quantidade de veículos a serem utilizados em uma demanda conhecida e frota homogênea. Fato que é corroborado por Manguino \& Ronconi, definindo que o Cálculo do tempo de ciclo corresponde ao somatório de todos os tempos que compõem a viagem.

Fabrício \& Subramanian (2008) apresentam um modelo de dimensionamento de frota Utilizando um modelo de programação inteira baseado no tempo de ciclo dos veículos em uma frota heterogênea para o atendimento à demanda de uma indústria de bebidas.

\subsection{Otimização}

De acordo com Longaray (2013) o modelo de otimização é um esquema lógico de representação de determinado problema organizado de forma a obter uma solução única e ótima. O modelo é uma representação simplificada do comportamento da realidade expressa na forma de equações matemáticas que serve para simular a realidade. (COLIN, 2007).

Relativo ao modelo de programação linear, o mesmo é estruturado com uma função-objetivo, que é uma função matemática que representa o principal objetivo do tomador de decisão, sendo que a mesma pode ser de minimização (de custos, 
erros, desvio de objetivos, etc.) ou de maximização (de lucro, receita, utilidade, riqueza, etc.), juntamente com a função objetivo temos as restrições, que são regras que dizem quais as limitações dos recursos ou atividades associadas ao modelo. (COLIN, 2007).

Segundo Colin (2007) um problema de programação inteira pode ser visto como um problema de programação linear mais uma restrição que indica que as variáveis devem ser números inteiros. O autor também esclarece que existem duas classes importantes de números inteiros: os números inteiros genéricos $(1,2,3 \ldots)$ e os números inteiros 0 e 1, esses últimos representam fenômenos do tipo sim e não, verdadeiro e falso, presença e ausência, aberto e fechado, etc.

\section{METODOLOGIA}

À luz de Roesch (2013), o presente trabalho se enquadra como pesquisa aplicada, pois se propõe a buscar soluções potenciais para problemas humanos. Especificamente, o trabalho busca encontrar um ponto ótimo no serviço de transporte de uma empresa de logística rodoviária que utiliza uma frota mista (caminhões próprios e contratados).

Quanto ao delineamento da pesquisa, a mesma se enquadra como um estudo de caso, sendo esse método uma estratégia de pesquisa que busca examinar um fenômeno contemporâneo dentro de seu contexto, sendo utilizada de maneira descritiva (buscando associações entre variáveis, normalmente com evidência de caráter quantitativo).

De tal forma o método de pesquisa adotado para alcançar a solução do problema foi a modelagem matemática, sendo o estudo desenvolvido em um operador logístico situado na cidade de Simões filho no Estado da Bahia, sendo as informações necessárias para a realização do trabalho obtidas através de documentos e relatórios escritos cedidos pela organização, onde tomou-se conhecimento das peculiaridades e características da operação, tais como:

- custo de frete: Valor pago aos veículos terceirizados para veicular 32 tons de produtos. O valor pago varia de acordo com a distância e peso da carga do cliente; 
- demanda: representa a quantidade de carga em unidade de peso que o cliente solicita o deslocamento. O valor da demanda mensal por cliente foi obtida através da multiplicação do número de containers solicitados por mês pelo peso médio em tonelada solicitado pelo mesmo cliente;

- distância: distância percorrida pelo veículo para realizar o transporte entre o cliente e o porto de Salvador, BA. Tomou-se como procedimento somar à distância ao cliente com mais $29 \mathrm{~km}$ (distância do operador logístico até o porto) e após multiplicar por dois, indicando a saída e retorno ao mesmo local;

- tempo de viagem: Representa o número de dias ou fração destes que compreende todo o ciclo operacional de transporte. Esse ciclo é composto pelos tempos de carregamento, transporte, descarregamento e retorno do veículo;

- custo: Valor da utilização dos veículos próprios divididos em fixos e variáveis.

As informações levantadas estão relacionadas no anexo A.

\section{MODELO PROPOSTO}

Esta seção discorre sobre o modelo de programação inteira proposta para a resolução do problema de pesquisa. Segue-se em sequência, a descrição do processo de formulação do problema, a execução do algoritmo e a análise de resultados.

\subsection{Formulações do problema}

O problema proposto refere-se à minimização de custos através de um dimensionamento de frota que atenda com satisfação a quantidade de cargas demandadas pelos clientes. A demanda deve ser totalmente atendida e representa 0 total que cada cliente solicita de serviço de transporte no espaço de um mês.

Conforme mencionado anteriormente, $\mathrm{O}$ estudo foi efetuado em um operador logístico situado na cidade de Simões filho, BA. Este Operador logístico atende 
exclusivamente oito clientes mensalmente, onde pelo menos um exige a utilização de veículos próprios do operador logístico devido a certificações de qualidade deste, somam-se a isso os valores da empresa que prevêem independência quanto a suas operações, fatos que pressupõem a necessidade da existência de uma frota própria mínima na organização.

As operações de transporte são efetuadas através de modal rodoviário, onde são utilizados veículos próprios e veículos terceiros. A empresa possui vinte e quatro veículos em sua frota, sendo que destes, treze são conjuntos articulados com capacidade somada de cinquenta toneladas cada um e os onze restantes são conjuntos trucados com capacidade de trinta e duas toneladas, esses veículos possuem custos fixos e variáveis; o requisito para prestação de serviço junto a esse operador logístico por parte de veículos terceiros é a capacidade de transporte dessas mesmas 32 toneladas, quando o veículo terceiro é contratado para realização de um transporte, essa operação apresenta apenas custos variáveis, que são determinadas pela distância e peso transportado.

Nas atuais operações a programação das operações é realizada manualmente priorizando-se a utilização de veículos próprios e baseadas no conhecimento empírico dos responsáveis. Os principais aspectos a ser considerados são a capacidade do veículo e a duração do ciclo operacional.

Quanto a capacidade do veículo,tendo em vista as características da carga (peso/volume), pode ocorrer superlotação ou baixo aproveitamento da capacidade, o primeiro indicando o não atendimento da demanda e o segundo o sub aproveitamento de recursos, tal aspecto gera uma restrição de capacidade mínima necessária para o atendimento da demanda mensal.

No tocante ao ciclo operacional (carregamento, transporte, descarregamento e retorno a base),ocorre uma restrição temporal que indica o limite mensal de dias trabalhados de acordo com o modelo do veículo. À vista disso, para os veículos articulados foi estipulado o limite de 21 dias, admitindo-se que os mesmos não trabalham no final de semana devido a restrições por parte dos órgãos que gerenciam o setor de transporte e subtraindo ainda de seu limite de dias, um dia para eventuais manutenções; do mesmo modo, seu tempo de ciclo foi arredondado para dias inteiros pelo modelo de veículo ter operação restrita do nascer ao por do 
sol. Da mesma forma, o limite estipulado de dias trabalhados dos veículos trucados pertencentes a frota foi de 23 dias, admitindo-se que os mesmos não trabalham no domingo e subtraindo de seu limite, um dia para manutenções. Logo, admite-se a velocidade média dos veículos no cumprimento da operação de transporte em 60 $\mathrm{km} / \mathrm{h}$.

\subsection{Formulações matemática}

A formulação matemática baseia-se no modelo proposto por Fabrício \& Subramanian (2008), tendo como parâmetros os expostos abaixo:

$C F$ v Custo fixo do veículo v.

$C V$ v Custo variável do veículo $v$.

Cap v Capacidade do veículo v.

Cap $T$ Capacidade do veículo Terceiro.

Dist ${ }_{i j} \quad$ Distância em quilômetros entre origem $\mathrm{i}$ e destino $\mathrm{j}$.

$D_{i j} \quad$ Demanda por produto da origem i para o destino $\mathrm{j}$.

$F_{i j} \quad$ Custo de frete da origem $\mathrm{i}$ até $\mathrm{o}$ destino $\mathrm{j}$.

$T_{i j} \quad$ Tempo de viagem (ciclo) entre a origem i e o destino j.

\section{Variáveis de decisão:}

${ }^{X}$ ijv Número de viagens realizadas pelo veículo $v$ com origem em $\mathrm{i}$ e destino em j.

$Z_{i j} \quad$ Número de viagens utilizando veículos terceirizados para atender a demanda entre a origem i e o destino j.

$Y$ v Variável binária que indica a soma dos custos fixos $(Y=1)$, ou não $(\mathrm{Y}=0)$ quando é um veículo $\mathrm{v}$ a efetuar o transporte. 


\section{Função Objetivo:}

A função objetivo (1) minimiza os custos totais de transporte. A introdução da variável binária de decisão ${ }^{Y}$ v na função objetivo garante que os custos fixos $\left(\begin{array}{ll}C F & v\end{array}\right)$ sejam contabilizados apenas se o veículo $v$ for utilizado.

$$
\sum_{i} \sum_{j} F_{i j} Z_{i j}+\sum_{i} \sum_{j} \sum_{v} \operatorname{DIST}_{i j} X_{i j v}+\sum_{v} C F_{v} Y_{v}
$$

\section{Restrições:}

A capacidade de atendimento é um fator importante no dimensionamento da frota. A mesma é dada conforme as restrições (2), a qual garante que a quantidade a ser atendida seja igual ou maior que a demanda do cliente.

$$
\sum_{v} X_{i j v} \operatorname{cap}{ }_{v}+Z_{i j} \operatorname{cap} T \geq D_{i j} \quad \forall i j
$$

As restrições (3) dizem respeito à disponibilidade da frota, assegurando que o número total de viagens, multiplicado pelo tempo de duração de cada viagem seja menor ou igual ao número total de dias úteis disponíveis para cada tipo de veículo ( $\mathrm{N}=23$ conjuntos traçados, $\mathrm{N}=21$ para rodo-trens). Ao tempo de cada viagem (ida e volta) é somado o tempo de carga e descarga, assim como é somado o tempo de deslocamento até o porto de Salvador- BA, o que indica que o veículo deve sair e retornar para a unidade após a operação. Do mesmo modo a restrição (3) é o fator que indica a soma do custo fixo do veículo à função objetivo, incluindo o custo a F. $O$ sempre que o número de dias trabalhados pelo veículo seja igual o maior a um.

$$
\sum_{i} \sum_{j} X_{i j v} T_{i j} \leq N \quad \forall i j
$$

As restrições (4), (5) e (6) são relativas à natureza das variáveis de decisão:

$$
\begin{array}{ll}
X_{i j v} \in Z+ & \forall i, j, v \\
Y_{v} \in\{0,1\} & \forall v
\end{array}
$$




$$
Z_{i j} \in Z^{+} \quad \forall i, j
$$

\subsection{Execução do algoritmo}

O algoritmo foi implementado no software LP SOLVER 2013, de distribuição livre. Foram utilizados dados correspondentes a um ano divididos em períodos mensais. Os testes foram realizados em um microcomputador DELL, com processador Intel core i3, disco rígido de 1 TB e memória de 4 GB.

\subsection{Análise do resultado do modelo proposto}

A implementação do modelo proposto ocasionou a redução dos custos totais relacionados a frota, da média de, trezentos e onze mil setecentos e dezoito Reais, para a média de Cento e vinte sete mil quinhentos e cinquenta e dois reais. Conforme ilustra o gráfico na figura 1, que apresenta a redução percentual média dos custos citados de $59 \%$ ao longo do período.

Figura 1 - Comparativo entre custo real e do modelo

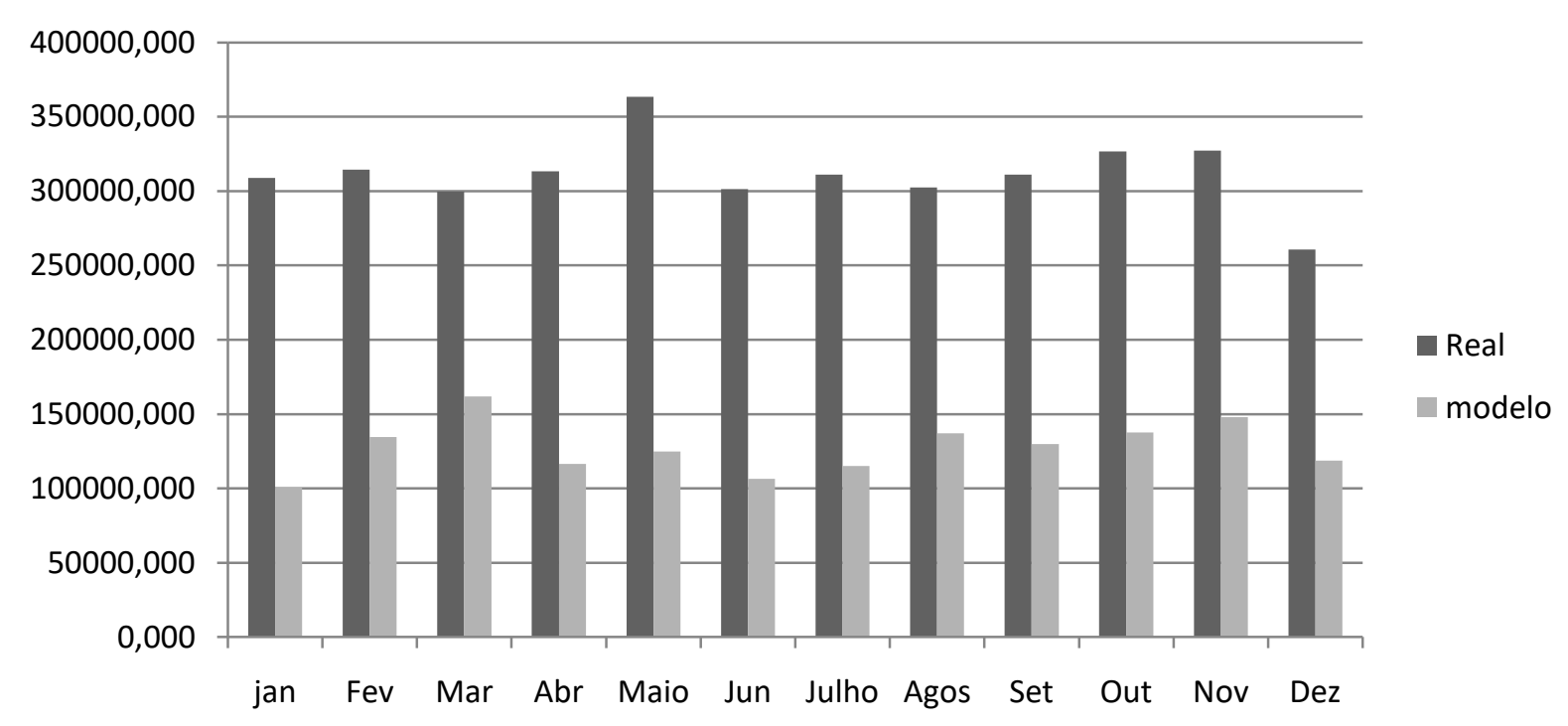

Fonte: Autores (2019)

Os resultados apresentados indicaram um dimensionamento excessivo da frota 
própria, sendo verificado conforme figura 2,a redução da frota real em $63 \%$. Assim sendo, o modelo indica que a quantidade de veículos necessários para atendimento da demanda apresentada seria em média de um terço dos veículos da frota real. Tal perspectiva indica que o sistema real que a empresa vem trabalhando gerando custos operacionais excessivos e desnecessários.

Figura 2 - Comparativo da dimensão da frota real e modelo

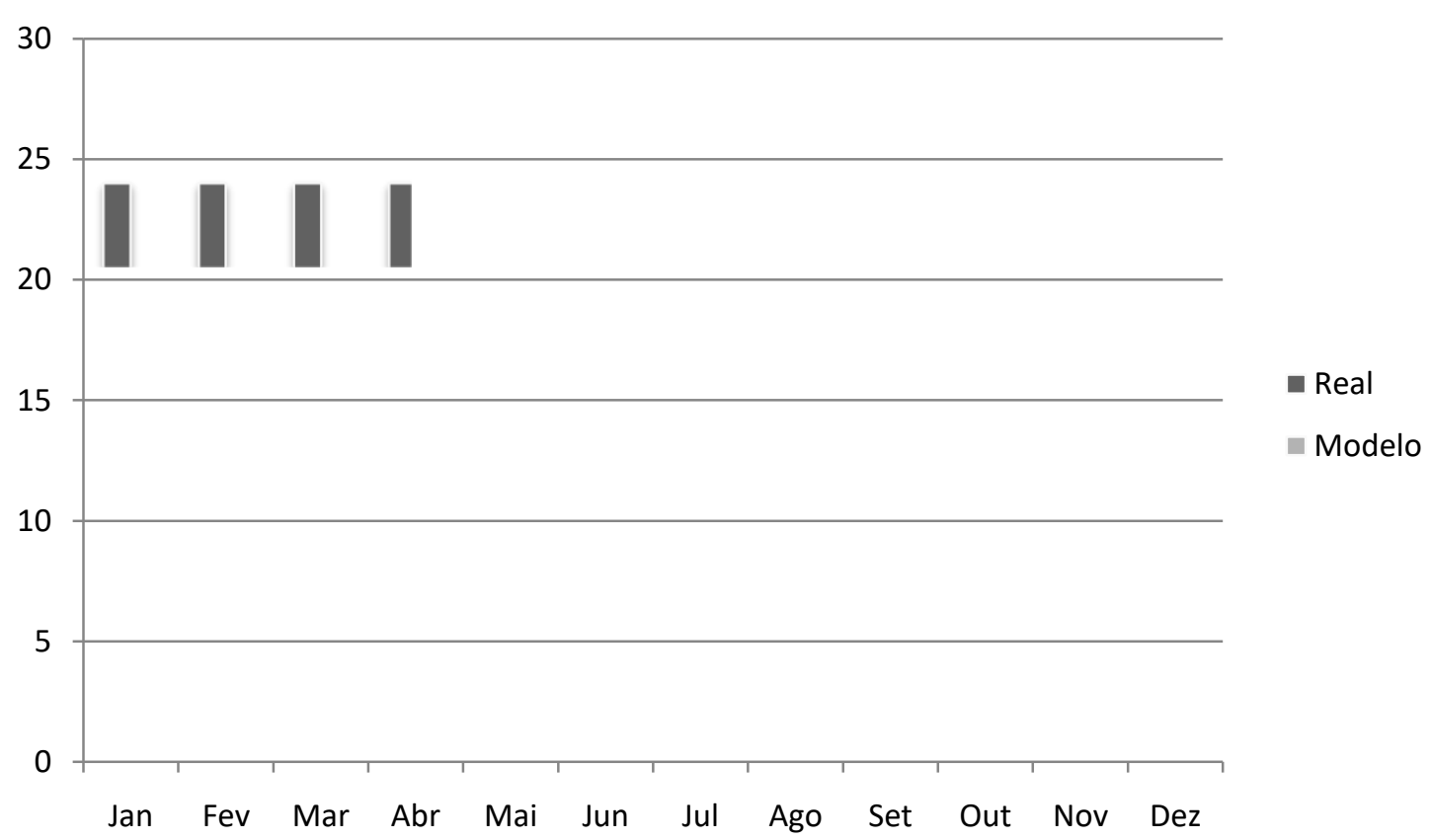

Fonte: Autores (2019).

O modelo ainda verificou a vantagem na utilização de veículos terceiros para o atendimento de carregamentos específicos, conforme a distribuição sazonal da demanda dos clientes,visando o melhor aproveitamento da frota do modelo e reduzindo a necessidade da propriedade de uma frota própria maior que a média estipulada, devida a uma possível alteração temporária desta mesma demanda, conforme a figura 3. A utilização de veículos terceiros, apesar de ser prevista pela empresa e ter seu frete tabelado, não vinha ocorrendo devido os responsáveis pelas operações entenderem que máxima utilização da frota, que se mostrou superdimensionada, escoaria seus custos fixos. 
Figura 3 - utilização de veículos terceiros

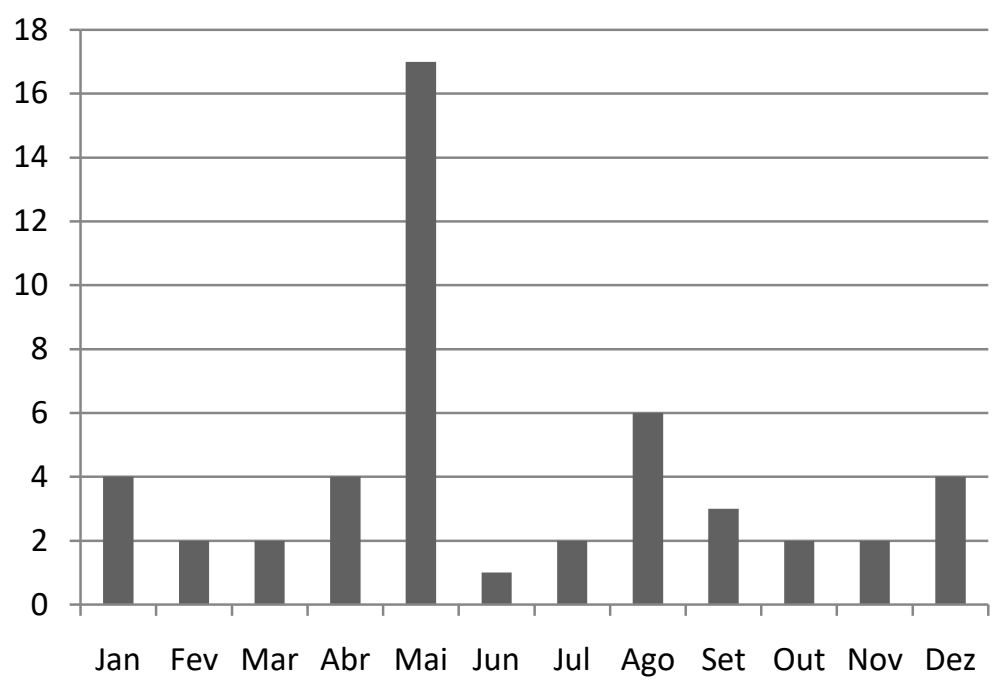

viagens de terceiros no período

Fonte: Autores (2019)

O alcance de um dimensionamento que ocasiona a redução dos custos totais em mais de 50\%, indica quais veículos devem atender a determinados clientes e aponta a possibilidade de atendimento de determinadas cargas por veículos contratados, atestam o alcance do objetivo do estudo.

\section{CONSIDERAÇÕES FINAIS}

No presente trabalho foi analisado o problema de dimensionamento de frota em um operador logístico de atuação no nordeste brasileiro, com base na cidade de Simões filho, na Bahia. Para responder ao problema apresentado foi utilizado um modelo de programação inteira, que foi testado no intervalo de um ano dividido em meses. O modelo proposto obteve redução de custos na média de $59 \%$ e verificou um dimensionamento excessivo em $63 \%$ na frota própria e, para sanar esse superdimensionamento indicou o tamanho necessário para a frota em cada período analisado.

O modelo proposto, o método de resolução e análise do problema, são exemplos dentre diversos apresentados pela pesquisa operacional para a resolução de questões semelhantes. Assim como a ferramenta computacional utilizada que pode ser substituída por diversas outras ferramentas disponíveis no mercado para o auxilio na resolução destas mesmas questões. 
O trabalho atingiu seus objetivos, pois foi possível identificar as características e particularidades da empresa estudada e através da verificação destas, utilizar o algoritmo de programação inteira para alcançar um dimensionamento de frota ideal para o atendimento da demanda desta empresa, fato que viabiliza a ferramenta de estudo.

Como limitação, o trabalho apresenta o fato de ser baseado em uma empresa específica, com todas suas particularidades, no entanto,o mesmo pode ser adaptado e utilizado tendo como objetos de estudo diferentes tipos de empresa, com atuação em área semelhante e que busquem responder dúvidas equivalentes.

Outro fato limitador do trabalho é a divisão do período estudado, de um ano, em meses; questão que surgiu do pouco tempo para a realização do trabalho e que tem como consequência a não a observação dos confrontos entre as demandas diárias dos clientes e o ciclo de viagem dos veículos, gerando um resultado no modelo que pode ser considerado otimista, caso posto frente a particularidades reais com menor folga de tempo.

Vale ressaltar, que o estudo se focou em uma solução de nível tático, que considera a utilização dos recursos da empresa, no caso, o dimensionamento e utilização da frota da empresa. Para novos trabalhos, sugere-se o aprofundamento no mesmo nível de operação, enriquecendo o estudo com a utilização de períodos mais curtos, sejam estes semanais ou diários, de forma a se reduzir o tempo de folga para atendimento da demanda, utilizar o ciclo diário dos veículos, analisando o impacto de sua indisponibilidade na oferta de serviço da empresa de logística, aproximando ainda mais o modelo do contexto real.

Espera-se que o trabalho contribua para o setor logístico, pois foca em um assunto que é responsável por grande gasto de recursos e ainda pouco estudada dentro no setor do transporte no contexto brasileiro, que é o dimensionamento de frota. Do mesmo modo, se espera que o estudo inspire a realização de novos trabalhos na área, utilizando de diferentes tamanhos e realidades de mercado, contribuindo, dessa maneira, para a melhoria contínua do setor logístico de transporte rodoviário. 


\section{REFERÊNCIAS}

BANDEIRA, Renata Albergaria de Mello. Fatores de decisão de terceirização logística: análise baseada na percepção dos executivos.2009. 252 f. Tese. (Doutorado) - Programa de Pós-Graduação em Administração, Escola de Administração, Universidade Federal do Rio Grande do Su. Porto Alegre, 2009.

BARTH, Mateus Bergesch., MICHEL, Fernando Dutra. Dimensionamento de uma frota de veículos com foco na redução de custos: um estudo de caso. 2012. Disponível em : http://www.lume.ufrgs.br/bitstream/handle/10183/65663/000858006.pdf?sequence $=1$. Acesso em: 02 maio.2015.

BERTAGLIA, Paulo R. Logística e gerenciamento da cadeia de abastecimento. 2. ed. rev. São Paulo: Saraiva. 2008

CHOPRA, Sunil., MEINDL, Peter. Gerenciamento da cadeia de suprimentos estratégia, planejamento e operação. Tradução de Claudia Freire. São Paulo: Person Prentice Hall, 2003.

COLIN, Emerson Carlos . Pesquisa operacional: 170 aplicações em estratégia, finanças, logística, produção, marketing e vendas. Rio de Janeiro: LTC, 2007.

FABRÍCIO, Alexandre de Siqueira Figueiredo; SUBRAMANIAN, Anand. Um modelo de programação inteira para o problema de dimensionamento de frota própria em uma indústria de bebidas. In: ENCONTRO NACIONAL DE ENGENHARIA DE PRODUÇÃO, 28., 2008.

[Anais...]. 2008. Disponível em:

http://www.abepro.org.br/biblioteca/enegep2008 TN STO 069492 12104.pdf

FERREIRA FILHO, Hélio Raymundo; SOARES, Délcio Cravo; SILVA, Nayara Cristina Lima da; DOS SANTOS, Nayéslie Cristine Brandão; LIMA JUNIOR, Pedro da Silva; FERREIRA, Aline de Oliveira. A gestão estratégica de frotas como ferramenta para redução de custos logísticos: estudo de caso de uma empresa de transporte de bovinos. Disponível em: http://www.revistaespacios.com/a15v36n23/15362325.html .Acesso em: 15 jul. 2019.

LONGARAY, André Andrade. Introdução a pesquisa operacional. São Paulo: Saraiva, 2013.

MANGUINO, João L.V., RONCONI, Débora P. Problema de roteamento de veículos com frota mista, janelas de tempo e custos escalonados. In: CONGRESSO LATINO-

IBEROAMERICANO INVESGACIÓN OPERATIVA. 24. SIMPÓSIO BRASILEIRO DE PESQUISA OPERACIONAL. 28., 2012. [Anais...]. Rio de Janeiro, 2012. p.1718-1729. Disponível em: http://www.din.uem.br/ ademir/sbpo/sbpo2012/pdf/arq0305.pdf. Acesso em: 6 jun.2015.

ROESCH, Sylvia Maria Azevedo. Projeto de estágio e de pesquisa em administração. 3. ed. São Paulo: Atlas, 2013.

RUSSIANO, Almir Ribeiro. Modelo de Filas para dimensionamento de frota em uma empresa de energia elétrica, 2010. Dissertação (Mestrado em engenharia de produção) Universidade Federal de Pernambuco. Pernambuco. [Anais eletrônicos....]. Disponível em: http://repositorio.ufpe.br/bitstream/handle/123456789/5430/arquivo518 1.pdf?sequence=1\&i sAllowed=y. Acesso em: 01 jun. 2015. 
SILVA, Petronio Borges. Frota própria ou terceirizada: qual a melhor opção para entrega de mercadorias?. 2012. Disponível em: http://files.petronio.webnode.com/200000009-

03f4804f11/ARTIGO\%20FROTA\%20PR\%C3\%93PRIA\%20E\%20A\%20TERCEIRIZADA.pdf Acesso em: 20 maio 2015.

VALENTE, Amir Matar., NOVAES, Antônio Galvão., PASSAGLIA, Eunice., VIEIRA, Heitor. Gerenciamento de transporte e frotas. 2. ed. São Paulo: Cengage Learning, 2012.

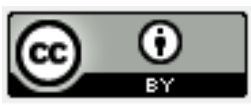

Artigo recebido em: 10/08/2019 e aceito para publicação em: 01/07/2021

DOI: http://dx.doi.org/10.14488/1676-1901.v21i2.3760 


\section{ANEXO A - Informações referentes ao modelo proposto}

Tabela 1 - Custo de frete ,em $\mathrm{R} \$$, pagos a veículos terceiros da origem ao destino.

\begin{tabular}{|c|c|c|c|c|c|c|c|}
\hline $\begin{array}{c}\text { Cliente } \\
\text { A }\end{array}$ & Cliente B & Cliente C & $\begin{array}{c}\text { Cliente } \\
\text { D }\end{array}$ & Cliente E & Cliente F & Cliente G & Cliente H \\
\hline $\begin{array}{c}\text { Dias } \\
\text { D'Avila } \\
\text { - BA }\end{array}$ & $\begin{array}{c}\text { Feira de } \\
\text { Sant'ana - } \\
\text { BA }\end{array}$ & $\begin{array}{c}\text { Camaçar } \\
\text { - BA }\end{array}$ & $\begin{array}{l}\text { Lagarto } \\
\text { - SE }\end{array}$ & $\begin{array}{c}\text { Luis E. } \\
\text { Magalhães } \\
\text { - BA }\end{array}$ & $\begin{array}{c}\text { Pedra Azul } \\
\text { - MG }\end{array}$ & $\begin{array}{c}\text { São } \\
\text { Francisco - } \\
\text { BA }\end{array}$ & $\begin{array}{c}\text { Camaçar } \\
\text { - BA }\end{array}$ \\
\hline 915,00 & 880,00 & 2450,00 & 1542,50 & 3800,00 & 2950,00 & 1062,00 & 1349,43 \\
\hline
\end{tabular}

Fonte: Autores (2019)

Tabela 2 - Custo variável, em $\mathrm{R} \$$, dos veículos v referentes ao período.

\begin{tabular}{|c|c|c|c|c|c|c|c|c|c|c|c|c|}
\hline & $\begin{array}{c}\text { Jan/ } \\
14\end{array}$ & $\begin{array}{c}\text { Fev/ } \\
14\end{array}$ & $\begin{array}{c}\text { Mar/ } \\
14\end{array}$ & $\begin{array}{c}\text { Abr/ } \\
14\end{array}$ & $\begin{array}{c}\text { Maio/ } \\
14\end{array}$ & $\begin{array}{c}\text { Jun/ } \\
14\end{array}$ & $\begin{array}{c}\text { Jul/ } \\
14\end{array}$ & $\begin{array}{c}\mathrm{Ago} / \\
14\end{array}$ & $\begin{array}{c}\text { Set/ } \\
14\end{array}$ & $\begin{array}{c}\text { Out/ } \\
14\end{array}$ & $\begin{array}{c}\text { Nov/ } \\
14\end{array}$ & $\begin{array}{c}\text { Dez/ } \\
14 \\
\end{array}$ \\
\hline Rodo A & 3,64 & 1,67 & 11,92 & 1,31 & 1,44 & 1,26 & 1,65 & 1,48 & 2,73 & 1,45 & 1,95 & 4,19 \\
\hline Rodo B & 0,94 & 1,29 & 0,92 & 2,18 & 1,64 & 0,92 & 1,56 & 1,50 & 1,01 & 1,90 & 1,51 & 1,79 \\
\hline Rodo C & 1,01 & 1,22 & 0,89 & 1,16 & 0,78 & 0,99 & 1,38 & 1,06 & 1,34 & 1,08 & 1,06 & 2,41 \\
\hline Rodo D & 1,28 & 1,86 & 1,15 & 1,62 & 4,33 & 4,23 & 1,25 & 1,84 & 2,53 & 1,51 & 1,28 & 3,91 \\
\hline Rodo E & 1,69 & 1,44 & 1,24 & 2,22 & 1,89 & 1,52 & 1,32 & 5,00 & 1,35 & 1,88 & 1,53 & 1,72 \\
\hline Rodo F & 1,02 & 2,05 & 1,28 & 2,21 & 1,08 & 0,95 & 1,11 & 2,41 & 1,82 & 1,82 & 14,49 & 1,21 \\
\hline Rodo G & 3,11 & 1,44 & 1,36 & 1,81 & 1,63 & 1,52 & 1,48 & 1,41 & 1,38 & 9,37 & 2,59 & 2,87 \\
\hline Rodo H & 2,18 & 1,78 & 1,45 & 1,15 & 1,59 & 1,36 & 1,55 & 1,45 & 1,28 & 1,17 & 2,36 & 1,39 \\
\hline Rodo I & 2,74 & 1,46 & 2,68 & 1,30 & 4,60 & 3,00 & 1,29 & 1,17 & 1,27 & 1,97 & 1,64 & 1,45 \\
\hline Rodo J & 1,12 & 1,64 & 1,51 & 1,28 & 1,86 & 1,24 & 1,15 & 1,18 & 3,60 & 1,17 & 1,31 & 2,14 \\
\hline Rodo K & 1,53 & 1,43 & 0,97 & 1,92 & 1,49 & 2,24 & 1,49 & 1,44 & 1,29 & 2,59 & 1,31 & 1,43 \\
\hline Rodo L & 1,66 & 1,41 & 3,39 & 1,43 & 1,15 & 1,22 & 1,39 & 1,18 & 2,52 & 1,31 & 1,32 & 1,23 \\
\hline Rodo M & 1,58 & 1,31 & 1,13 & 1,13 & 1,11 & 1,95 & 1,08 & 1,91 & 1,34 & 1,13 & 1,15 & 1,87 \\
\hline $\begin{array}{c}\text { Trucado } \\
\text { A }\end{array}$ & 1,77 & 1,09 & 1,13 & 0,94 & 1,05 & 1,41 & 0,83 & 0,87 & 1,04 & 0,89 & 1,04 & 1,02 \\
\hline $\begin{array}{c}\text { Trucado } \\
\text { B }\end{array}$ & 0,90 & 0,89 & 1,11 & 1,66 & 1,35 & 0,88 & 1,30 & 0,80 & 0,94 & 1,12 & 0,70 & 1,29 \\
\hline $\begin{array}{c}\text { Trucado } \\
\text { C }\end{array}$ & 1,63 & 1,76 & 1,85 & 1,81 & 1,14 & 2,77 & 1,41 & 6,99 & 3,20 & 1,45 & 1,82 & 2,16 \\
\hline $\begin{array}{c}\text { Trucado } \\
\text { D }\end{array}$ & 2,35 & 2,91 & 1,52 & 1,06 & 0,93 & 1,06 & 1,20 & 0,95 & 1,43 & 1,07 & 1,53 & 1,09 \\
\hline $\begin{array}{c}\text { Trucado } \\
\text { E }\end{array}$ & 1,21 & 1,95 & 1,80 & 1,11 & 1,19 & 1,43 & 0,96 & 0,98 & 2,00 & 1,23 & 1,19 & 1,03 \\
\hline $\begin{array}{c}\text { Trucado } \\
\text { F }\end{array}$ & 1,33 & 1,52 & 1,38 & 1,00 & 1,10 & 1,56 & 2,07 & 1,03 & 1,36 & 1,36 & 1,47 & 1,22 \\
\hline $\begin{array}{c}\text { Trucado } \\
\text { G }\end{array}$ & 1,12 & 1,32 & 1,13 & 1,10 & 1,18 & 2,68 & 2,13 & 1,73 & 1,60 & 1,53 & 1,60 & 1,39 \\
\hline $\begin{array}{c}\text { Trucado } \\
\mathrm{H}\end{array}$ & 1,17 & 1,35 & 1,09 & 0,86 & 0,90 & 1,15 & 0,88 & 0,93 & 1,16 & 0,94 & 1,05 & 1,16 \\
\hline $\begin{array}{c}\text { Trucado } \\
\text { I }\end{array}$ & 1,49 & 1,25 & 1,22 & 1,04 & 0,89 & 0,99 & 0,96 & 2,95 & 1,23 & 1,90 & 2,20 & 2,20 \\
\hline $\begin{array}{c}\text { Trucado } \\
\mathrm{J}\end{array}$ & 0,92 & 1,20 & 1,44 & 1,48 & 0,90 & 0,91 & 0,89 & 0,85 & 0,95 & 0,87 & 1,02 & 1,01 \\
\hline $\begin{array}{c}\text { Trucado } \\
\text { K }\end{array}$ & 0,74 & 1,36 & 0,81 & 1,59 & 0,82 & 0,95 & 0,89 & 0,86 & 1,08 & 0,98 & 0,95 & 1,02 \\
\hline
\end{tabular}

Fonte: Autores (2019) 
Tabela 3 - Custos fixos, em $R \$$, dos veículos v no período.

\begin{tabular}{|c|c|c|c|c|c|c|c|c|c|c|c|c|}
\hline & Jan/14 & Fev/14 & Mar/14 & $A b r / 14$ & Maio/14 & Jun/14 & Jul/14 & Ago/14 & Set/14 & Out/14 & Nov/14 & Dez/14 \\
\hline Rodo A & 8063,50 & 8063,50 & 8148,50 & 8063,50 & 12877,59 & 6838,15 & 7423,01 & 6838,15 & 6838,15 & 6838,15 & 8199,41 & 5083,16 \\
\hline Rodo B & 7063,50 & 7789,55 & 7063,50 & 8464,55 & 12064,55 & 7105,52 & 7105,52 & 6621,49 & 6171,49 & 6171,49 & 7982,75 & 5061,50 \\
\hline Rodo C & 7710,25 & 8419,12 & 7710,25 & 8357 & 10646,72 & 6171,49 & 7520,39 & 7033,83 & 6171,49 & 7033,83 & 7532,75 & 5033,10 \\
\hline Rodo D & 9325,25 & 10570,09 & 9483,25 & 8019,75 & 8019,75 & 7240,16 & 7338,99 & 6808,99 & 6808,99 & 6808,99 & 8170,25 & 5080,25 \\
\hline Rodo $\mathrm{E}$ & 8328,50 & 8328,50 & 8413,50 & 8328,50 & 10383,67 & 7014,82 & 7014,82 & 7014,82 & 7014,82 & 7014,82 & 8376,08 & 5100,87 \\
\hline Rodo F & 7125,62 & 7063,50 & 9472,73 & 8802,00 & 8251,00 & 6171,49 & 7024,82 & 6171,49 & 6171,49 & 6171,49 & 7532,75 & 5016,50 \\
\hline Rodo G & 8326,00 & 9613,50 & 9613,50 & 9616,00 & 11668,67 & 7871,49 & 7871,49 & 7871,49 & 7013,15 & 7871,49 & 9232,75 & 5100,66 \\
\hline Rodo $\mathrm{H}$ & 8249,00 & 8126,00 & 8126,00 & 8126,00 & 8126,00 & 7779,82 & 9474,84 & 6879,82 & 7744,82 & 7759,36 & 9232,75 & 5087,33 \\
\hline Rodo I & 8127,50 & 8126,00 & 8126,00 & 8126,00 & 8126,00 & 7688,16 & 6879,82 & 6879,82 & 7624,82 & 7737,27 & 9232,75 & 5087,33 \\
\hline Rodo J & 8831,25 & 8769,75 & 8769,75 & 9413,50 & 8769,75 & 7738,16 & 7738,16 & 7308,99 & 7627,82 & 7738,16 & 9099,42 & 5173,17 \\
\hline Rodo K & 8251,00 & 8251,00 & 8251,00 & 8251,00 & 8251,00 & 6963,15 & 9794,91 & 6963,15 & 6963,15 & 6963,15 & 8324,41 & 5095,66 \\
\hline Rodo L & 8251,00 & 8251,00 & 8251,00 & 8316,09 & 11082,76 & 6963,50 & 6963,15 & 6963,15 & 6963,15 & 6963,15 & 8324,41 & 5095,66 \\
\hline Rodo M & 8949,65 & 8949,65 & 8949,65 & 9711,80 & 8949,65 & 7937,02 & 10303,01 & 6963,15 & 6963,15 & 7428,92 & 8324,41 & 5095,66 \\
\hline $\begin{array}{c}\text { Trucado } \\
\text { A }\end{array}$ & 7537,70 & 8267,04 & 8267,04 & 8267,54 & 7537,70 & 6862,94 & 6376,38 & 6376,38 & 6376,38 & 6884,48 & 7737,64 & 4771,39 \\
\hline $\begin{array}{c}\text { Trucado } \\
\text { B }\end{array}$ & 5879,58 & 7712,70 & 7712,70 & 7099,82 & 7037,70 & 6432,51 & 6432,51 & 6432,51 & 6043,04 & 6043,04 & 7404,30 & 4738,05 \\
\hline $\begin{array}{c}\text { Trucado } \\
\text { C }\end{array}$ & 8037,32 & 7975,20 & 7975,20 & 7562,32 & 7975,20 & 6668,04 & 9499,80 & 6668,04 & 6668,04 & 6668,04 & 8029,30 & 4800,55 \\
\hline $\begin{array}{c}\text { Trucado } \\
\text { D }\end{array}$ & 6787,70 & 7500,20 & 7500,20 & 7562,32 & 10225,20 & 8558,01 & 5876,38 & 5876,38 & 5876,38 & 5876,28 & 7237,64 & 4721,39 \\
\hline $\begin{array}{c}\text { Trucado } \\
\text { E }\end{array}$ & 8175,20 & 4025,20 & 4025,20 & 6849,82 & 10872,70 & 5876,38 & 6326,38 & 6326,38 & 6493,04 & 6326,38 & 7687,64 & 4756,39 \\
\hline $\begin{array}{c}\text { Trucado } \\
\text { F }\end{array}$ & 7500,20 & 6887,70 & 6787,70 & 9971,55 & 10225,20 & 6351,38 & 6351,38 & 5876,38 & 5876,38 & 5876,38 & 7237,64 & 4721,39 \\
\hline $\begin{array}{c}\text { Trucado } \\
\text { G }\end{array}$ & 6849,82 & 6787,70 & 6787,70 & 7513,75 & 9964,11 & 6360,41 & 6360,41 & 6360,41 & 5876,38 & 6360,41 & 7687,64 & 4721,39 \\
\hline $\begin{array}{c}\text { Trucado } \\
\mathrm{H}\end{array}$ & 7450,20 & 7450,20 & 7450,20 & 8162,70 & 11550,20 & 6318,04 & 8778,51 & 6318,04 & 6318,04 & 6318,04 & 7679,30 & 4765,55 \\
\hline $\begin{array}{c}\text { Trucado } \\
\text { I }\end{array}$ & 7512,32 & 8244,88 & 8244,88 & 8244,88 & 8244,88 & 6847,82 & 9308,29 & 6847,82 & 6318,04 & 6847,82 & 7679,30 & 4818,53 \\
\hline $\begin{array}{c}\text { Trucado } \\
\text { J }\end{array}$ & 5941,70 & 7706,04 & 7706,04 & 7706,04 & 7037,70 & 6488,60 & 6488,60 & 6488,66 & 6043,04 & 6488,60 & 7679,30 & 4738,05 \\
\hline $\begin{array}{c}\text { Trucado } \\
\mathrm{K}\end{array}$ & 4207,00 & 7832,38 & 7832,38 & 7832,38 & 7832,38 & 6488,60 & 6572,82 & 6572,86 & 6043,04 & 6572,82 & 7849,85 & 4738,05 \\
\hline
\end{tabular}

Fonte: Autores (2019) 
Tabela 4 - quilometragem do ciclo operacional para cada cliente.

\begin{tabular}{|c|c|c|c|c|c|c|c|}
\hline $\begin{array}{c}\text { Cliente } \\
\text { A }\end{array}$ & Cliente B & Cliente C & Cliente D & Cliente E & Cliente F & Cliente G & Cliente H \\
\hline $\begin{array}{c}\text { Dias } \\
\text { D'Avila } \\
\text { - BA }\end{array}$ & $\begin{array}{c}\text { Feira de } \\
\text { Sant'ana - } \\
\text { BA }\end{array}$ & $\begin{array}{c}\text { Camaçari } \\
\text { - BA }\end{array}$ & $\begin{array}{l}\text { Lagarto - } \\
\text { SE }\end{array}$ & $\begin{array}{l}\text { Luis E. } \\
\text { Magalhães } \\
\text { - BA }\end{array}$ & $\begin{array}{l}\text { Pedra Azul } \\
\text { - MG }\end{array}$ & $\begin{array}{c}\text { São } \\
\text { Francisco - } \\
\text { BA }\end{array}$ & $\begin{array}{c}\text { Camaçari - } \\
\text { BA }\end{array}$ \\
\hline 114,40 & 236,40 & 98 & 638 & 2032 & 1400 & 174,20 & 98 \\
\hline
\end{tabular}

Fonte: Autores (2019)

Tabela 5 - Tempo em dias do ciclo operacional dos veículos articulados (rodo-trens).

\begin{tabular}{|c|c|c|c|c|c|c|c|}
\hline Cliente A & Cliente B & Cliente C & Cliente D & Cliente E & Cliente F & Cliente G & Cliente H \\
\hline $\begin{array}{c}\text { Dias } \\
\text { D'Avila } \\
\text { - BA }\end{array}$ & $\begin{array}{c}\text { Feira de } \\
\text { Sant'ana - } \\
\text { BA }\end{array}$ & $\begin{array}{c}\text { Camaçari } \\
\text { - BA }\end{array}$ & $\begin{array}{l}\text { Lagarto - } \\
\text { SE }\end{array}$ & $\begin{array}{c}\text { Luis E. } \\
\text { Magalhães } \\
\text { - BA }\end{array}$ & $\begin{array}{c}\text { Pedra Azul } \\
\text { - MG }\end{array}$ & $\begin{array}{c}\text { São } \\
\text { Francisco - } \\
\text { BA }\end{array}$ & $\begin{array}{c}\text { Camaçari } \\
\text { - BA }\end{array}$ \\
\hline 1 & 1 & 1 & 1 & 2 & 2 & 1 & 1 \\
\hline
\end{tabular}

Fonte: Autores (2019)

Tabela 6 - Tempo em dias do ciclo operacional dos veículos trucados.

\begin{tabular}{cccccccc}
\hline Cliente A & Cliente B & Cliente C & Cliente D & Cliente E & Cliente F & Cliente G & Cliente H \\
\hline Dias & Feira de & Camaçari & Lagarto - & Luis E. & Pedra Azul & São & Camachanari \\
D'Avila & Sant'ana - & - BA & SE & - BA & - MG & BA & - BA \\
- BA & BA & & & 1,54 & 1,13 & 0,30 & 0,22 \\
0,27 & 0,35 & 0,22 & 0,60 & 13 & \\
\hline
\end{tabular}

Fonte: Autores (2019) 
Tabela 7 - Demanda em toneladas de produtos por cliente no período.

\begin{tabular}{|c|c|c|c|c|c|c|c|c|}
\hline & Cliente A & Cliente B & Cliente C & $\begin{array}{c}\text { Cliente } \\
\text { D }\end{array}$ & Cliente E & Cliente F & Cliente G & Cliente H \\
\hline Mês & $\begin{array}{c}\text { Dias } \\
\text { D'Avila } \\
\text { - BA }\end{array}$ & $\begin{array}{c}\text { Feira de } \\
\text { Sant'ana - } \\
\text { BA }\end{array}$ & $\begin{array}{c}\text { Camaçari } \\
\text { - BA }\end{array}$ & $\begin{array}{c}\text { Lagarto - } \\
\text { SE }\end{array}$ & $\begin{array}{c}\text { Luis E. } \\
\text { Magalhães - } \\
\text { BA }\end{array}$ & $\begin{array}{c}\text { Pedra } \\
\text { Azul- MG }\end{array}$ & $\begin{array}{c}\text { São } \\
\text { Francisco } \\
\text { - BA }\end{array}$ & $\begin{array}{c}\text { Camaçari } \\
\text { - BA }\end{array}$ \\
\hline $\begin{array}{c}\mathrm{Jan} / 1 \\
4\end{array}$ & 5268,82 & 1485 & 1368 & 146,25 & 34,52 & 115,6 & 123,6 & 441,72 \\
\hline $\begin{array}{c}\text { Fev/ } \\
14\end{array}$ & 4048 & 2331 & 1448,5 & 314,50 & 68 & 116 & 61,80 & 137,45 \\
\hline $\begin{array}{c}\text { Mar/ } \\
14\end{array}$ & 3804,10 & 2260,92 & 1331 & 35,40 & 51 & 138,72 & 123,60 & 148 \\
\hline $\begin{array}{c}\mathrm{Abr} / 1 \\
4\end{array}$ & 4065,85 & 2151 & 1595 & 88,50 & 26,4 & 92,48 & 61,68 & 55,5 \\
\hline $\begin{array}{c}\text { Mai/1 } \\
4\end{array}$ & 3472,55 & 2406,2 & 1694 & 159,30 & 51 & 54,80 & 100,30 & 115,56 \\
\hline $\begin{array}{c}\text { Jun/1 } \\
4\end{array}$ & 2512,8 & 1943,12 & 990 & 336,30 & 200,97 & 170,34 & 120,36 & 193,9 \\
\hline $\begin{array}{c}\text { Jul/ } \\
14\end{array}$ & 3071,2 & 2388,04 & 1243 & 106,20 & 70,08 & 180,36 & 160,42 & 55,4 \\
\hline $\begin{array}{l}\text { Ago } \\
\text { /14 }\end{array}$ & 2774,55 & 2469,76 & 1826 & 88,50 & 109,62 & 220,44 & 164,80 & 55,4 \\
\hline $\begin{array}{c}\text { Set/ } \\
14\end{array}$ & 4449,75 & 2197,36 & 1287 & 53,10 & 255,78 & 240,48 & 160,48 & 255,78 \\
\hline $\begin{array}{l}\text { Out } / 1 \\
4\end{array}$ & 4100,75 & 2578,72 & 1287 & 106,20 & 36,54 & 30,60 & 80,24 & 952,35 \\
\hline $\begin{array}{c}\text { Nov/ } \\
14\end{array}$ & 4379,95 & 1943,12 & 902 & 53,10 & 146,16 & 51 & 80,24 & 1102 \\
\hline $\begin{array}{c}\text { Dez/ } \\
14\end{array}$ & 5339,70 & 1861,4 & 825 & 53,10 & 86,58 & 70,14 & 80,24 & 1247 \\
\hline
\end{tabular}

Fonte: Autores (2019) 